\title{
Prognostic significance of plasma osteopontin level in breast cancer patients
}

\author{
Hanan R. Nassar ${ }^{1}$, Alfred E. Namour ${ }^{1}$, Hanan E. Shafik ${ }^{1}$ Amr S. El Sayed², \\ Samar M. Kamel ${ }^{3}$, Manar M. Moneer ${ }^{4}$, Nadia I. Zakhary ${ }^{5}$ \\ 'Department of Medical Oncology, National Cancer Institute, Cairo University, \\ Egypt \\ ${ }^{2}$ Department of Biochemistry, Faculty of Science, Cairo University, Egypt \\ ${ }^{3}$ Department of Biochemistry, Faculty of Science, Helwan University, Egypt \\ ${ }^{4}$ Department Epidemiology and Biostatistics, National Cancer Institute, Cairo \\ University
}

${ }^{5}$ Department of Cancer Biology, National Cancer Institute, Cairo University

\begin{abstract}
Many studies have demonstrated that osteopontin (OPN) contributes functionally to aggressive behaviour in many tumours including breast cancer.

This study aims to investigate its role as a simple biochemical marker easily measured in plasma of breast cancer patients to give an early signal for metastases and to detect its relationship to clinicopathological findings and survival.

We measured plasma OPN, CA15.3 and serum alkaline phosphatase (ALP) activity in 55 patients, 28 with early stage breast cancer and 27 with bone metastasis out of whom 20 had metastasis in other sites. The median age at diagnosis for non-metastatic cases was 60 years (range $35-85$ ) and for metastatic cases was 45.5 years (range 32-59). In the non-metastatic group, $78.57 \%$ of the patients were histologically graded as grades I and II and $21.43 \%$ as grade III tumours. In the metastatic group, $81.48 \%$ of the patients had grades I and II and $18.52 \%$ had grade III tumours; $54 \%$ of patients in the non-metastatic group were at stage II and $46 \%$ were at stage III at presentation. All patients of group II had bone metastasis, 33\% had liver metastases, $25.9 \%$ had lung metastasis and $14.8 \%$ had lymph node metastasis.

Patients with non-metastatic disease had a median OPN level of $55 \mathrm{ng} / \mathrm{ml}$ (range $54-150 \mathrm{ng} / \mathrm{l}$ ), while those in the metastatic group had a median of $148.0 \mathrm{ng} / \mathrm{l}$ (range $56.0-156.0 \mathrm{ng} / \mathrm{l})$, a difference which was statistically significant $(P=0.001)$. There was no statistically significant difference in the median levels of CA15.3 and ALP between both groups.

The median OPN level was significantly higher with serum ALP level above 90, progesterone receptor (PR) status, bone and visceral metastasis. Median OPN was not affected significantly by menopausal status ( $P$-value 0.3$)$, tumour grade ( $P$-value 0.3$)$, estrogen receptor (ER) status ( $P$-value 0.7$)$, pathological type $(P$-value 0.42$)$ or serum CA15.3 level $(P$-value 0.6$)$.

At the end of 12 -year follow-up, $83 \%$ of the patients survived (92.3\% in the non-metastatic versus $74.1 \%$ in the metastatic group). The estimated median survival for the whole study population at 12 years was 13 years ( $95 \% \mathrm{Cl} 8.144-17.856)$. The estimated median survival was 13 years $(95 \% \mathrm{Cl} 0$ ) and 12 years (95\% $\mathrm{Cl} 4.893-19.11)$ in patients with median OPN levels of $<142$ and $\geq 142$, respectively, a difference which was not statistically significant $(P=0.343)$. No statistically significant difference in overall survival $0 \mathrm{~S}$ was noticed in relation to menopausal status $(P=0.7)$, pathological type $(P=0.4)$ and hormone receptor status $(P=0.3)$. At 6-year follow-up, it was found that OS was affected by the presence of visceral metastasis, tumour grade, serum plasma level of ALP and the serum level of CA15.3 ( $P=0.0006,0.007,0.001$ and 0.03 , respectively). However, the presence of bone metastasis did not affect OS $(P=0.6)$.

Osteopontin level can be a simple biochemical marker easily measured in plasma of breast cancer patients to give early signals for metastases, but not a prognostic factor for survival.
\end{abstract}

Keywords: Breast cancer • Ostepontin • Metastasis • Tumour progression

(C) De Gruyter Open

\footnotetext{
*E-mail: ezzathanan@yahoo.com
} 


\section{Introduction}

Breast cancer is by far the most common cancer among women from both developed and developing countries. It accounts for $22.9 \%$ of all female cancers. It is also the leading cause of cancer death in females accounting for $13.7 \%$ of their cancer-related mortality. The favourable incidence to mortality ratio $(3: 1)$ can be attributed to the more favourable survival in developed regions (3.7:1) than less developed regions (2.7:1) [1]. In Egypt, breast cancer is estimated to be the most common cancer among females accounting for $37.7 \%$ of total cancer cases. It is also the leading cause of cancerrelated mortality accounting for $29 \%$ of cancer deaths $[2,3]$. These estimates are confirmed in many regional Egyptian cancer registries as well as in hospital-based frequencies [2, 3, 4].

Metastasis is a multistep process requiring the expression of specific genes. In addition, it requires cooperation of numerous molecules and the coordinated expression of many protein products. Different carcinomas have distinct patterns of metastases. Breast cancer tumour cells disseminate very early to bone [5]. When breast cancer cells metastasise into the skeleton, they cause either osteolytic or osteoblastic lesions. Both lesions are often accompanied by bone pain and increased bone fragility causing extended suffering [6]. In general, $65-75 \%$ of breast cancer patients with advanced disease will develop bone relapse, leading to highly devastating conditions including pain, pathological fractures and spinal cord compression, ultimately decreasing the quality of life. Surveillance and prompt detection of early bone metastases can prevent the development of such complications [7]. Imaging techniques are now used to diagnose bone metastases, but they are expensive, and expose patients to toxic and radioactive compounds. This raises the importance of developing new bone metabolic markers that can aid in diagnose bone metastases [8].

Osteopontin is a secreted integrin-binding glycophosphoprotein produced in a variety of tissues. Its association with cancer has been well documented. Many studies have demonstrated that OPN contributes functionally to aggressive cell behaviour, tumour progression and metastasis [9]. OPN is a phosphorylated glycoprotein found in all body fluids, extracellular matrix components and proteinaceous matrix of mineralised tissues. This protein was detected in approximately $90 \%$ of primary breast carcinomas and its overexpression is related with breast cancer evolution and metastases. Thus the synthesis of OPN by tumour cells may play a role in the promotion of bone metastases [10]. However, much less is known about the prognostic significance of OPN in early breast cancer or when OPN levels rise during breast cancer progression.

This study aims ultimately to investigate its role as a simple non-invasive biochemical marker that could be easily measured in plasma of breast cancer patients to give early signals for metastases and to detect a relationship between the OPN plasma level and clinicopathological findings and survival.

\section{Patients and Methods}

Fifty-five patients were included in this study. They were classified into two groups. A non-metastatic group comprising 28 patients with early stage breast cancer, without any evidence of metastatic disease, and a metastatic group comprising 27 patients with bone metastasis, with or without metastasis in other sites.

All patients involved in the present study were informed with a written consent explaining the design of the work, which was approved by the Institutional Review Board (IRB) ethical committee of the National Cancer Institute $(\mathrm{NCl})$, which follows the rules of Helsinki IRB. Clinical data were recorded from the outpatient files in the medical oncology department of $\mathrm{NCl}$-Cairo University. Patients were followed every 3 to 4 weeks for women on active chemotherapy and every 6 to 12 weeks for patients after chemotherapy or on hormone therapy. The median duration of follow-up was 12 years.

OPN level in plasma was determined using ELISA technique; the kit was purchased from Quantikine. Breast-cancer-associated antigen (CA15.3) in serum was determined using chemiluminescent-based technique of Elecsys 2010. The kit was purchased from Roche diagnostics, and serum ALP activity was determined according to the kinetic method of Deutschen Gesellschaft (1972), using the kit manufactured by Globe Diagnostics. The multiple receiver operating characteristic (ROC) curve was drawn to evaluate the cutoff point for the three markers to improve the specificity and sensitivity of the studied parameters (Table 1).

All patients were subjected to routine laboratory investigations including complete blood picture, liver function and kidney function.

\section{Statistical methods}

Data was analysed using IBM SPSS advanced statistics version 20 (SPSS Inc., Chicago,Illinois). The ROC curve was drawn, to improve the specificity and sensitivity of the studied parameters. Chi-square test (Fisher's 
Table 1. The cutoff values, sensitivity and specificity of each parameter investigated for group I versus group II.

\begin{tabular}{c|ccc}
\hline Parameter & Cutoff value & Sensitivity & Specificity \\
\hline \hline${ }^{*}$ CA15.3 & 25.15 & $52.4 \%$ & $62.5 \%$ \\
${ }^{*}$ ALP & 123.2 & $68.2 \%$ & $69.2 \%$ \\
${ }^{*}$ OPN & 104.875 & $96.4 \%$ & $92.6 \%$ \\
\hline
\end{tabular}

${ }^{*}$ CA15.3: Breast-cancer-associated antigen

${ }^{\star} A L P$ : serum alkaline phosphatase

*OPN: Osteopontin

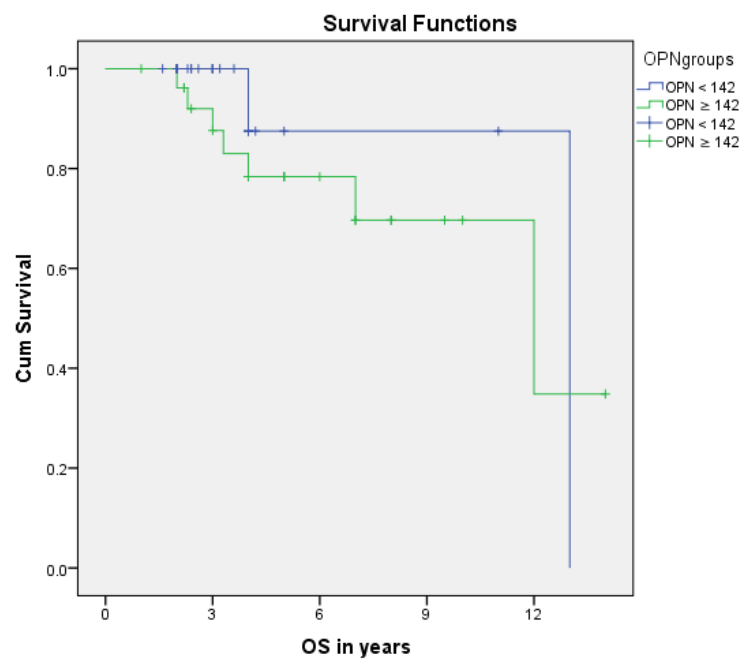

Figure 1. Effect of the median OPN level on survival. $P=0.343$

exact test) was used to examine the relation between qualitative variables. Survival analysis was done using the Kaplan-Meier method and comparison between two survival curves was done using the log-rank test. A $p$-value $<0.05$ was considered significant.

\section{Results}

We measured plasma OPN in 55 patients, 28 with early stage breast cancer and 27 with bone metastasis out of whom 20 had, in addition, metastasis in sites other than bone. The median age at the time of diagnosis for nonmetastatic cases was 60 years (range 35-85) and for metastatic cases was 45.5 years (range $32-59$ ). In the non-metastatic group, $82.14 \%$ of patients had invasive duct carcinoma, $7.14 \%$ had invasive lobular carcinoma and $10.72 \%$ had mixed invasive duct carcinoma and invasive lobular carcinoma, while in the metastatic group $85.18 \%$ of the patients had invasive duct carcinoma,
$7.14 \%$ had invasive lobular carcinoma and $7.41 \%$ had mixed invasive duct and lobular carcinoma. In the non-metastatic group, $78.57 \%$ of the patients were histologically graded as grades I and II tumours and $21.43 \%$ as grade III tumours. In the metastatic group, $81.48 \%$ of the patients were graded as grades I and II tumours and $18.52 \%$ as grade III tumours.

As regards stage of the disease, $54 \%$ of patients in the non-metastatic group were stage II and $46 \%$ were stage III at presentation. All patients of group II had bone metastasis, 33\% had liver metastases, $25.9 \%$ had lung metastasis and $14.8 \%$ had lymph node metastasis; these data are detailed in Table 2.

The median OPN level in the whole study population was $142 \mathrm{ng} / \mathrm{l}$ (range 54.0-156 ng/l). Patients with non-metastatic disease had a median OPN level of $55.0 \mathrm{ng} / \mathrm{ml}$ (range 54.0-150.0 ng/ml), while those in the metastatic group had a median of $148.0 \mathrm{ng} / \mathrm{l}$ (range 56.0-156.0 ng/l). The level of OPN in plasma of patients with metastasis was found to be significantly higher as compared to its corresponding level in non-metastatic patients $(p=0.001)$. There was no statistically significant difference in the median levels of CA15.3 and ALP between both groups (Table 3).

On analysing the relation between the median OPN level and different prognostic factors in the whole study population, it was found that the median OPN level was significantly higher with serum ALP level above 90 and from 40 to 90 , PR status, bone and visceral metastasis. Median OPN was not affected significantly by menopausal status ( $P$-value 0.3 ), tumour grade $(P$-value 0.3$)$, ER status ( $P$-value 0.7$)$, pathological typing $(P$-value 0.42$)$ or serum CA15.3 level ( $P$-value $0.6)$; see Table 4.

We tested whether the survival of the patients was related to the OPN plasma level. Fig. 1 shows the Kaplan-Meier adjusted survival estimates of patients grouped into two according to the median OPN level (lower than 142 and $\geq 142$ ). At the end of 12-year follow-up for the whole study population, $83 \%$ of the patients survived $(92.3 \%$ in non-metastatic versus $74.1 \%$ in metastatic patients). The estimated median survival for the whole study population at 12 years was 13 years. (95\% Cl 8.144-17.856). The estimated median survival was 13 years $(95 \% \mathrm{Cl} 0)$ and 12 years $(95 \%$ Cl 4.893-19.11) in patients with median OPN levels of $<142$ and $\geq 142$, respectively. The difference was not statistically significant $(P=0.343)$. No statistically significant difference in OS was noticed in relation to menopausal status $(P=0.7)$, pathological typing $(P=0.4)$ and hormone receptor status $(P=0.3)$. At 6-year follow-up, it was found that OS was affected 
Table 2. Clinicopathological characteristics of both groups.

\begin{tabular}{|c|c|c|c|c|}
\hline \multirow[t]{2}{*}{ Clinicopathological factors } & \multicolumn{2}{|c|}{ Group I } & \multicolumn{2}{|c|}{ Group II } \\
\hline & $\mathrm{n}$ & $\%$ & $\mathrm{n}$ & $\%$ \\
\hline \multicolumn{5}{|l|}{ Histopathological type } \\
\hline $\begin{array}{c}{ }^{*} \mid \mathrm{DC} \\
{ }^{*} \mathrm{LC} C \\
\text { Mixed }{ }^{*} \mathrm{DCC} /{ }^{*} \mid \mathrm{LC} \\
\end{array}$ & $\begin{array}{c}23 \\
2 \\
3 \\
\end{array}$ & $\begin{array}{c}(82.14 \%) \\
(7.14 \%) \\
(10.72 \%) \\
\end{array}$ & $\begin{array}{c}23 \\
2 \\
2 \\
\end{array}$ & $\begin{array}{l}(85.18 \%) \\
(7.41 \%) \\
(7.41 \%) \\
\end{array}$ \\
\hline \multicolumn{5}{|l|}{ Grade } \\
\hline | and || & 22 & $(78.57 \%)$ & 22 & $(81.48 \%)$ \\
\hline III & 6 & $(21.43 \%)$ & 5 & $(18.52 \%)$ \\
\hline \multicolumn{5}{|l|}{ Stage } \\
\hline II and III & 28 & $(100.00 \%)$ & 0 & $(00.00 \%)$ \\
\hline IV & 0 & $(0.00 \%)$ & 27 & $(100.00 \%)$ \\
\hline $\begin{array}{l}\text { Menopausal status } \\
\text { Premenopausal } \\
\text { Postmenopausal }\end{array}$ & $\begin{array}{l}17 \\
11\end{array}$ & $\begin{array}{l}(60.71 \%) \\
(39.29 \%)\end{array}$ & $\begin{array}{l}16 \\
11\end{array}$ & $\begin{array}{l}(59.26 \%) \\
(40.74 \%)\end{array}$ \\
\hline $\begin{array}{l}{ }^{*} \text { ER/*PR status } \\
\text { Both positive } \\
\text { Either positive } \\
\text { Both negative } \\
\text { Unknown }\end{array}$ & $\begin{array}{l}19 \\
3 \\
3 \\
3\end{array}$ & $\begin{array}{l}(67.87 \%)) \\
(10.71 \%) \\
(10.71 \%) \\
(10.71 \%)\end{array}$ & $\begin{array}{c}16 \\
4 \\
4 \\
3\end{array}$ & $\begin{array}{l}(59.25 \%) \\
(14.82 \%) \\
(14.82 \%) \\
(11.11 \%)\end{array}$ \\
\hline $\begin{array}{c}\text { Metastatic sites } \\
\text { Bone } \\
\text { Liver } \\
\text { Lung } \\
\text { Nodes }\end{array}$ & $\begin{array}{l}0 \\
0 \\
0 \\
0\end{array}$ & $\begin{array}{l}(0.00 \%) \\
(0.00 \%) \\
(0.00 \%) \\
(0.00 \%)\end{array}$ & $\begin{array}{c}27 \\
9 \\
7 \\
4\end{array}$ & $\begin{array}{c}(100 \%) \\
(33.33 \%) \\
(25.92 \%) \\
(14.81 \%)\end{array}$ \\
\hline
\end{tabular}

*IDC: Invasive duct carcinoma

* ER: Estrogen receptor

*ILC: Invasive lobular carcinoma

${ }^{*}$ PR: Progesteron receptor

Table 3. Median value of markers in both groups.

\begin{tabular}{c|ccc}
\hline Items & Group I & Group II & P-value \\
\hline \hline $\begin{array}{c}{ }^{*} \mathrm{CA} 15.3(\mathrm{u} / \mathrm{ml}) \\
\text { Median (Range) }\end{array}$ & $24.1(13.0-110.0)$ & $25.3(2.3-421.9)$ & 0.774 \\
\hline $\begin{array}{c}{ }^{*} \mathrm{ALP}(\mathrm{u} / \mathrm{l}) \\
\text { Median (Range) }\end{array}$ & $100.0(46.0-287.0)$ & $149.0(41.0-763)$ & 0.367 \\
\hline $\begin{array}{c}{ }^{*} \text { OPN(ng/ml) } \\
\text { Median (Range) }\end{array}$ & $55.0(54.0-150.0)$ & $148.0(56.0-156.0)$ & $<0.001$ \\
\hline
\end{tabular}

${ }^{*}$ CA15.3: Breast-cancer-associated antigen

*ALP: serum alkaline phosphatase

*OPN: Osteopontin

by the presence of visceral metastasis, tumour grade, serum plasma level of ALP and the serum level of CA15.3 $(P=0.0006,0.007,0.001$ and 0.03 , respectively) . However the presence of bone metastasis did not affect OS $(P=0.6)$.

\section{Discussion}

Osteopontin is a matricellular protein produced by multiple tissues in the human body and is most abundant in bone [11]. Several studies have shown that OPN levels may be elevated in cancer, both in tumour tissue and in patients' blood [12]. Osteopontin is highly expressed in a variety of tumours and appears to be a prognostic factor correlating with poor prognosis and reduced survival [13]. It has been demonstrated that the plasma OPN level is significantly higher in patients with metastatic breast cancer compared to patients who are on clinical follow-up after completion of adjuvant therapy for early breast cancer [14, 15, 16].

Fifty-five patients were included in this study, 28 presented with stages II or III and 27 patients with stage IV; stage I is rare in Egyptian patients with breast cancer presenting to $\mathrm{NCl}$. Our median OPN level for metastatic patients was $148 \mathrm{ng} / \mathrm{l}$ (range 56-156 ng/l), 
Table 4. Relation between the median OPN level and clinicopathological factors.

\begin{tabular}{|c|c|c|c|c|}
\hline Clinicopathological factors & Osteopontin level $<142$ & Osteopontin level $\geq 142$ & Total & P- value \\
\hline $\begin{array}{c}\text { Menopausal status } \\
\text { Pre } \\
\text { Post }\end{array}$ & $\begin{array}{l}18(55 \%) \\
10(45 \%)\end{array}$ & $\begin{array}{l}15(45 \%) \\
12(55 \%)\end{array}$ & $\begin{array}{l}33 \\
22\end{array}$ & 0.3 \\
\hline $\begin{array}{c}\text { CA15.3 level } \\
\text { up to } 22.4 \\
>22.4\end{array}$ & $\begin{array}{l}3(23 \%) \\
5(31 \%)\end{array}$ & $\begin{array}{l}10(77 \%) \\
11(69 \%)\end{array}$ & $\begin{array}{l}13 \\
16 \\
\end{array}$ & 0.6 \\
\hline $\begin{array}{c}\text { ALP } \\
40-90 \\
>90 \\
\end{array}$ & $\begin{array}{c}12(46 \%) \\
4(22 \%) \\
\end{array}$ & $\begin{array}{l}14(54 \%) \\
18(88 \%) \\
\end{array}$ & $\begin{array}{l}26 \\
22 \\
\end{array}$ & 0.04 \\
\hline $\begin{array}{l}\text { Grade } \\
1 \text { and } 2 \\
3\end{array}$ & $\begin{array}{c}23(52 \%) \\
4(36 \%)\end{array}$ & $\begin{array}{l}21(48 \%) \\
7(64 \%)\end{array}$ & $\begin{array}{l}44 \\
11\end{array}$ & 0.3 \\
\hline $\begin{array}{c}\text { PR } \\
\text { Positive } \\
\text { Negative } \\
\end{array}$ & $\begin{array}{l}24(62 \%) \\
2(18 \%) \\
\end{array}$ & $\begin{array}{c}15(38 \%) \\
9(82 \%) \\
\end{array}$ & $\begin{array}{l}39 \\
11 \\
\end{array}$ & 0.01 \\
\hline $\begin{array}{c}\text { ER } \\
\text { Positive } \\
\text { Negative } \\
\end{array}$ & $\begin{array}{c}20(53 \%) \\
4(45 \%) \\
\end{array}$ & $\begin{array}{c}18(47 \%) \\
5(55 \%)\end{array}$ & $\begin{array}{c}38 \\
9\end{array}$ & 0.7 \\
\hline $\begin{array}{c}\text { Metastatic } \\
\text { Non-metastatic }\end{array}$ & $\begin{array}{c}4(15 \%) \\
23(82 \%)\end{array}$ & $\begin{array}{c}23(85 \%) \\
5(18 \%)\end{array}$ & $\begin{array}{l}27 \\
28\end{array}$ & 0.001 \\
\hline
\end{tabular}

a value which is consistent with those reported by Vivien et al., who reported a median of $142 \mathrm{ng} / \mathrm{l}$ (range 138-1,312 ng/mL) for metastatic cases [17]. In our study, the median OPN level for early breast cancer was $55 \mathrm{ng} / \mathrm{l}$ (range 54-150 ng/l), while Vivien et al. reported a median of $47 \mathrm{ng} / \mathrm{mL}$ (range 22-122 ng/mL) [16]. The OPN blood level was also reported by others to be elevated in various cancers. Kim et al. reported that plasma OPN levels were significantly higher $(P$ $<0.01$ ) in 51 patients with epithelial ovarian cancer (487 ng/ mL) compared with 107 healthy controls (147 ng/mL) [18]. Saeki et al. reported similar findings in 30 cases of multiple myeloma [19]. In a series of 100 men with hormone refractory prostate cancer, Hotte et al. have shown that OPN plasma levels correlate independently and negatively with OS $(P=0.029)$ and the median OPN level was $198.5 \mathrm{ng} /$ $\mathrm{mL}$ (range 15-2,363 ng/mL) [20]. The plasma OPN level was also found to be an independent prognostic factor for survival in 54 patients with squamous carcinomas of the head and neck [21]. Ang et al. reported that OPN plasma levels were elevated in 72 patients with transitional cell carcinoma of the bladder and were associated with the disease stage [22]. In our study, no significant relation was found between the OPN plasma level and menopausal status, tumour grade, ER status, pathological type or CA15.3. However, there is a highly significant relation between the OPN level and PR negativity $(P=0.01)$. Neill et al. reported that high
OPN expression was associated with high tumour grade and poor prognosis and that expression levels predicted local recurrence, disease-free survival and bone metastases [23]. Our study demonstrated a significant correlation between the OPN level and ALP serum level $(p=0.04)$. Hemant et al. reported that the OPN level correlated with serum ALP; $p=0.001$ [15]. Vivein et al. reported that there was no correlation between plasma OPN levels and relapse-free survival (RFS) or OS [16], a finding which is consistent with our results. A study by Hemant et al. reported that a high plasma OPN level is associated with shorter survival $(p=0.001)$ [15]. In this study, a statistically significant association between the OPN level and visceral metastases was demonstrated and OS was statistically lower in this group of patients $(p=0.0006)$. There was also a relation between OS and high tumour grade $(p=0.007)$ and between high CA15.3 serum level and OS $(p=0.03)$. No relation was found between OS and menopausal status, pathological type or hormonal status.

\section{Conclusion}

The OPN level can be an easily measured biochemical marker. It can be used as an early signal for metastases, but not a prognostic factor for survival. This raises the importance of conducting more clinical trials addressing this issue. 
[1] Ferlay J, Shin HR, Bray F, Forman D, Mathers C, Parkin DM. GLOBOCAN 2008 v1. 2, Cancer Incidence and Mortality Worldwide: IARC Cancer Base No. 10. Lyon, France: International Agency for Research on Cancer [available from], <http:// www.globocan.iarc.fr/factsheets/cancers/breast. asp>; 2010 [accessed on 24.09.2012].

[2] The National Cancer Registry Program of Egypt (NCRPE). Reports and Statistics: Aswan, Damietta \& El-Minia [available from], <http://www. cancerregistry.gov.eg/reports.aspx> [accessed 5.09.2012].

[3] The Gharbiah Population-based Cancer Registry (GPCR). Cancer in Egypt, Gharbiah [available from], <http://www.emro.who.int/ncd/pdf/cancer registry_Egypt.pdf>; 2007 [accessed 5.09.2012].

[4] Ali-eldin N. Cancer statistics 2002-2007: Preliminary report [online], <http://www.nci.cu.edu.eg/lectures/ Cancer_statistics.pdf> [accessed 5.09.2012].

[5] Clohisy JC, Frazier E, Hirayama T, Abu-Amer Y. RANKL is an essential cytokine mediator of polymethylmethacrylate particle-induced osteoclastogenesis. J Orthop Res. 2003; 21: 202212.

[6] Munday GR. Metastasis to bone: causes, consequences and therapeutic opportunities. Nat Rev Cancer. 2002; 2(8): 584-93.

[7] Bohn LO, Nasir I, Brufsky A, Tseng GC, Bhargava R. Biomarker profile in breast carcinomas presenting with bone metastasis. Int J Clin Exp Pathol. 2010; 3(2): 139-146.

[8] Koizumi M, Ogata E. Bone metabolic markers as gauges of metastasis to bone: a review. Annals of Nuclear Medicine. 2002; 16 (3): 161-168.

[9] Bellahcene A, Castronovo V, Ogbureke K U, Fisher LW, Fedarko NS. Small integrin-binding ligand $\mathrm{N}$-linked glycoproteins (SIBLINGs): Multifunctional proteins in cancer. Nat Rev Cancer. 2008; 8: 212226.

[10] Rodrigues L, Jose' A, Teixeira F, Schmitt L, Marie $P$. The role of osteopontin in tumor progression and metastasis in breast cancer. Cancer Epidemiol Biomarkers Prev. 2007; 16(6): 1087-97.

[11] Shevde LA, Das S, Clark DW, Samant RS. Osteopontin: an effector and an effect of tumor metastasis. Curr Mol Med. 2010; Feb: 10(1): 7181.

[12] Furger KA, Menon RK, Tuck AB, Bramwell VH, Chambers AF: The functional and clinical roles of osteopontin in cancer and metastasis. Curr Mol Med. 2001; 1: 621-632.
[13] Fedarko NS, Jain A, Karadag A, Van Eman MR, Fisher LW. Elevated serum bone sialoprotein and osteopontin in colon, breast, prostate, and lung cancer. Clin Cancer Res. 2001; 7: 4060-6.

[14] Senger DR, Perruzzi CA, Gracey CF, Papadopoulos A, Tenen DG. Secreted phosphoproteins associated with neoplastic transformation: close homology with plasma proteins cleaved during blood coagulation. Cancer Res. 1988; 48: 5770-4.

[15] Hemant S, Diosdado SB, Katia ST, Fraces PO, Alan BT, et al. Elevated plasma osteopontin in metastatic breast cancer associated with increased tumor burden and decreased survival. Clinical Cancer Research 1997; 3: 605-611.

[16] Vivien HC, Alan BT, Judith AW, Pieter HA, Car OP, et al. Assessment of Osteopontin in early breast cancer, correlative study in a randomized clinical trial. Breast Cancer Research. 2014;16R8 (10): 1188.

[17] Vivien HC, Gordon S D, Alan BT, Sylvia MW, Katia ST, Anna T et al. Serial Plasma Osteopontin Levels Have Prognostic Value in metastatic breast cancer, Clin Cancer Res. 2006; 12: 3337-3343.

[18] Kim JH, Skates SJ, Uede T, Kohri K, Tozawa $\mathrm{K}$, Okamura $\mathrm{T}$ et al. Osteopontin as a potential diagnostic biomarker for ovarian cancer. JAMA. 2002; 287: 1671-9.

[19] Saeki Y, Mima T, Ishii T, Ogata A, Ohshima S, Kobayashi $\mathrm{H}$ et al. Enhanced production of osteopontin in multiple myeloma: clinical and pathogenic implications. Br J Haematol. 2003; 123: 263-70.

[20] Hotte SJ, Winquist EW, Stitt L, Wilson SM, Chambers AF. Plasma osteopontin: associations with survival and metastasis to bone in men with hormone refractory prostate carcinoma. Cancer. 2002; 95: 506-12.

[21] Le QT, Sutphin PD, Raychaudhuri S, Yu SC, Terris DJ, Lin HS, et al. Identification of osteopontin as a prognostic plasma marker for head and neck squamous cell carcinomas. Clin Cancer Res. 2003; 9: 59-67.

[22] Ang C, Chambers AF, Tuck AB, Winquist E, Izawa JI. Plasma osteopontin levels are predictive of disease stage in patients with transitional cell carcinoma of the bladder. Br J Urol Int. 2005; 96: 803-5.

[23] Neill P, Fadi J, Wen J, Kefah M. Osteopontin expression profiles predict pathological and clinical outcome in breast cancer. Anti-Cancer Res. 2008;28: 4105-10. 